\title{
Anthropometric measures at different ages and endometrial cancer risk
}

\section{Dal Maso*, I,2 , A Tavani ${ }^{3}$, A Zucchetto', M Montella ${ }^{4}$, M Ferraroni ${ }^{2}$, E Negri ${ }^{3}$, J Polesel', A Decarli ${ }^{2}$, R Talamini', C La Vecchia ${ }^{2,3}$ and S Franceschi ${ }^{5}$}

'SOC Epidemiologia e Biostatistica, Centro di Riferimento Oncologico, 3308 I Aviano (PN), Italy; ${ }^{2}$ Dipartimento di Medicina del Lavoro, Sezione Statistica Medica e Biometria 'GA Maccacaro', Università degli Studi di Milano, 20133 Milano, Italy; ${ }^{3}$ Dipartimento di Epidemiologia, Istituto di Ricerche Farmacologiche 'Mario Negri', 20156 Milano, Italy; 'Senvizio di Epidemiologia, Istituto Tumori 'Fondazione Pascale', 80131 Napoli, Italy; ${ }^{5}$ International Agency for Research on Cancer, 69372 Lyon, France

BACKGROUND: Endometrial cancer is strongly associated with body mass index (BMI), but the influence of BMI history and of different types of obesity is uncertain.

METHODS: A case-control study was carried out in Italy including 454 cases and 908 controls admitted to hospital for acute non-hormone-related conditions. Odds ratios (ORs) and 95\% confidence intervals (Cls) were computed using multivariate logistic and spline regression models.

RESULTS: The OR for BMI $>30$ at diagnosis compared with 20 to $<25 \mathrm{~kg} \mathrm{~m}^{-2}$ was 4.08 (95\% Cl: 2.90-5.74). The association for BMI was monotonic with a possible steeper increase for BMI above 28. Conversely, waist-to-hip ratio (WHR) showed a bell shaped curve with increased OR (2.10;95\% Cl: 1.43-3.09) in the intermediate tertile only. After stratification by BMl at diagnosis, history of weight loss and $\mathrm{BMI}$ at age 30 did not influence endometrial cancer risk. History of obesity in middle age had a weak and not significant adverse effect among obese women ( $\mathrm{OR}=1.60 ; 95 \% \mathrm{Cl}$ : 0.52-4.96).

CONCLUSION: The predominant importance of recent weight compared to lifetime history, justifies encouraging weight reduction in women at any age.

British Journal of Cancer (2011) 104, 1207-1213. doi:I0.1038/bjc.2011.63 www.bjcancer.com

Published online 8 March 2011

(c) 20II Cancer Research UK

Keywords: endometrial cancer; body mass index; waist-to-hip ratio; case-control studies

Endometrial cancer is strongly associated with overweight and obesity (Levi et al, 1992; La Vecchia et al, 1997; Calle et al, 2003), which account for $30 \%(\sim 16000$ new cases per year $)$ of cases among European women (Renehan et al, 2010). This association reflects the relationship between adiposity and high levels of unopposed oestrogens, which derive from increased frequency of anovulatory cycles (in pre-menopausal women) or the enhanced conversion of adrenal androgens into oestrogens in adipose tissue (in postmenopausal women; Key and Pike, 1988; Parazzini et al, 1991). The excess risk for endometrial cancer increases with age, reflecting the increasing importance of androgen conversion as ovarian activity has ceased (Key and Pike, 1988; Parazzini et al, 1991).

Some studies have suggested that, among women of normal body mass index (BMI) at diagnosis, there is little additional excess risk of endometrial cancer in relation to history of overweight (Le Marchand et al, 1991; Levi et al, 1992; Shu et al, 1992; Swanson et al, 1993; Olson et al, 1995; Terry et al, 1999; Weiderpass et al, 2000; Schouten et al, 2004; Xu et al, 2005; Trentham-Dietz et al, 2006; Chang et al, 2007; Friedenreich et al, 2007; WCRF/AICR - World Cancer Research Fund/American Institute for Cancer Research, 2007; Park et al, 2010). However,

*Correspondence: Dr L Dal Maso, E-mail: epidemiology@cro.it Received 5 October 20 0; revised II January 20 I I; accepted 3 February 20I I; published online 8 March 20II data on the relationship between lifetime changes in BMI and endometrial cancer risk are limited and difficult to assess because a monotonic pattern (gradual weight increases during life) predominates in most studied populations (Le Marchand et al, 1991; Levi et al, 1992; Swanson et al, 1993; Olson et al, 1995; $\mathrm{Xu}$ et al, 2005, 2006; Park et al, 2010). Similarly, there is limited information on the influence on endometrial cancer risk of different types of obesity, in particular, waist-to-hip ratio (WHR) (WCRF/AICR - World Cancer Research Fund/American Institute for Cancer Research, 2007). In some studies from Europe (Friedenreich et al, 2007), North America (Austin et al, 1991; Schapira et al, 1991; Swanson et al, 1993; Goodman et al, 1997), and China (Shu et al, 1992; Xu et al, 2005), BMI and waist circumference were stronger predictors of endometrial cancer risk than WHR, but the issue remains open to discussion.

To further explore these issues, we used data on BMI at different ages and measures of waist and hip at diagnosis from a case-control study on endometrial cancer carried out in different parts of Italy (Zucchetto et al, 2009).

\section{MATERIALS AND METHODS}

A case-control study on endometrial cancer was conducted between 1992 and 2006 in three Italian areas: Pordenone and Milan in the north and Naples in the south (Lucenteforte et al, 2008; 
Zucchetto et al, 2009). Cases were 454 women (median age 60 years, range 18-79 years) with histologically confirmed endometrial cancer and no previous history of cancer; those diagnosed less than 1 year before recruitment were eligible. Controls were 908 women (median age 61 years, range 19-79 years) admitted to the same network of hospitals of cases for a wide spectrum of nonneoplastic, acute illnesses. Women with a history of hysterectomy or admitted for gynaecological or hormone-related conditions were not eligible as controls. The reasons for hospital admission among controls were trauma (36\%), orthopaedic diseases $(32 \%)$, acute surgical conditions (9\%), and other illnesses (eye, nose, ear, skin, or dental disorders, 23\%). Cases and controls were frequency matched on study centre and 5-year age, with a $1: 2$ ratio.

Centrally trained staff interviewed eligible women during their hospital stay. Less than $5 \%$ of the approached cases and controls refused the interview. The response rates were similar across hospitals and geographic areas. All interviews were conducted using a structured questionnaire, which included information on age, education and other socioeconomic factors, physical activity, smoking habit, alcohol intake, a validated food frequency questionnaire, a problem-oriented medical history, and history

Table I Distribution of 454 endometrial cancer cases and 908 controls according to selected variables, Italy, 1992-2006

\begin{tabular}{|c|c|c|c|c|}
\hline & \multicolumn{2}{|c|}{ Cases } & \multicolumn{2}{|c|}{ Controls } \\
\hline & No. & $\%$ & No. & $\%$ \\
\hline \multicolumn{5}{|l|}{ Age (years) } \\
\hline$<50$ & 67 & 14.8 & 134 & 14.8 \\
\hline $50-59$ & 140 & 30.8 & 280 & 30.8 \\
\hline $60-69$ & 166 & 36.6 & 332 & 36.6 \\
\hline$\geqslant 70$ & 81 & 17.8 & 162 & 17.8 \\
\hline \multicolumn{5}{|l|}{ Study center } \\
\hline Áviano-Pordenone & 237 & 52.2 & 474 & 52.2 \\
\hline Milan & 140 & 30.8 & 280 & 30.8 \\
\hline Naples & 77 & 17.0 & 154 & 17.0 \\
\hline \multicolumn{5}{|l|}{ Education (years) } \\
\hline$<7$ & 263 & 57.9 & 553 & 60.9 \\
\hline $7-11$ & 119 & 26.2 & 225 & 24.8 \\
\hline$\geqslant 12$ & 72 & 15.9 & 130 & 14.3 \\
\hline \multicolumn{5}{|l|}{ Smoking status } \\
\hline Never & 331 & 72.9 & 647 & 71.3 \\
\hline Current & 75 & 16.5 & 157 & 17.3 \\
\hline Former & 48 & 10.6 & 104 & 11.5 \\
\hline \multicolumn{5}{|l|}{ Age at menarche (years) ${ }^{\mathrm{a}}$} \\
\hline$<11$ & 24 & 5.3 & 44 & 4.9 \\
\hline $11-13$ & 283 & 62.6 & 475 & 52.7 \\
\hline $14-16$ & 137 & 30.3 & 345 & 38.3 \\
\hline$\geqslant 17$ & 8 & 1.8 & 38 & 4.2 \\
\hline \multicolumn{5}{|l|}{ Parity } \\
\hline Nulliparous & 68 & 15.0 & 126 & 13.9 \\
\hline Parous & 386 & 85.0 & 782 & 86.1 \\
\hline \multicolumn{5}{|l|}{ Oral contraceptive use } \\
\hline Never & 408 & 89.9 & 790 & 87.0 \\
\hline Ever & 46 & 10.1 & 118 & 13.0 \\
\hline \multicolumn{5}{|c|}{ Hormone replacement therapy } \\
\hline Never & 405 & 89.2 & 830 & 91.4 \\
\hline Ever & 49 & 10.8 & 78 & 8.6 \\
\hline \multicolumn{5}{|l|}{ Menopausal status ${ }^{\mathrm{a}}$} \\
\hline Pre/peri & 85 & 19.2 & 174 & 19.3 \\
\hline Post & 358 & 80.8 & 726 & 80.7 \\
\hline
\end{tabular}

aThe sum does not add up to the total because of some missing values. of cancer in first degree relatives. In a detailed section of the questionnaire, women were asked to report their height and weight at 1 year before cancer diagnosis or interview (for controls; referred to, for brevity, as measures at diagnosis), weight at age 30 and 50 years, lifelong highest and lowest weight, and perceived body size at age 12 years (i.e., thinner than, same as, heavier than peers). BMI was computed as weight divided by squared height $\left(\mathrm{kg} \mathrm{m}^{-2}\right)$. The interviewers measured the circumference of the waist $(2 \mathrm{~cm}$ above the umbilicus) and hip (maximal protrusion) at the time of interview and computed WHR. Waist-to-height ratio (WHtR) was also computed. Waist or hip could not be measured in $89 \%$ of women interviewed in Milan centre, leading to a lack of information for WHR and WHtR in $33 \%$ of cases and $35 \%$ of controls. However, in the overall study, median BMI in women with a measured WHR was not substantially different from that in women for whom the information on WHR or WHtR was missing (26.4 and 26.2, respectively, among cases and 26.1 and 25.8 among controls).

Table 2 Distribution of 454 endometrial cancer cases and 908 controls, and corresponding odds ratio (OR) with $95 \%$ confidence intervals $(\mathrm{Cls})^{a}$, according to body mass index (BMI) at diagnosis and at different ages, ${ }^{b}$ Italy, 1992-2006

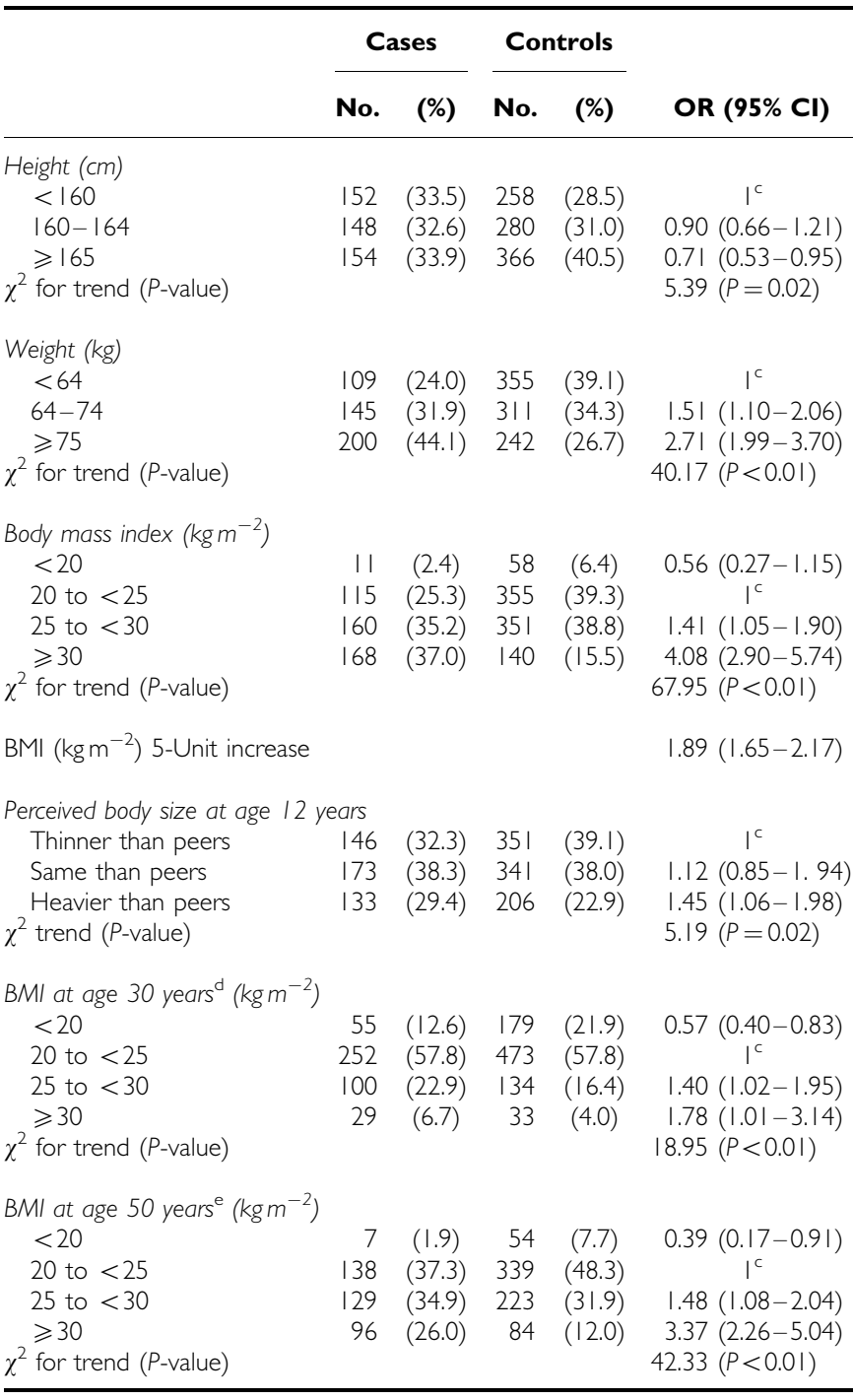

${ }^{a}$ ORs from conditional logistic regression models, conditioned on age and study centre, adjusted for year of interview, education, smoking status, age at menarche, age at menopause, oral contraceptive use, parity, and hormone replacement therapy use. 'The sum does not add up to the total because of some missing values. 'Reference category. ${ }^{d}$ Women $\geqslant 30$ years old only. ${ }^{e}$ Women $\geqslant 50$ years old only. 
Standard BMI categories $(<20,20$ to $<25,25$ to $<30$, and $\geqslant 30 \mathrm{~kg} \mathrm{~m}^{-2}$ ) were used to facilitate comparisons with previous studies. Tertiles obtained from the combined distribution of cases and controls were used to assess other anthropometric measures. A conditional logistic regression model was used to compute odds ratios (ORs) and the corresponding 95\% confidence intervals (CIs). All analyses were conditioned on age and study centre and adjusted for calendar period of interview, years of education, smoking habits, age at menarche and at menopause, parity, and use of oral contraceptives and hormone replacement therapy. Additional adjustment for alcohol intake, and occupational and recreational physical activity did not materially modify the risk estimates. To avoid potentially arbitrary categorisations, the 'dose-risk' relationship between BMI at diagnosis or WHR and endometrial cancer risk was assessed using logistic cubic regression splines (Greenland, 1995; Rosenberg et al, 2003; Dal Maso et al, 2007), and appropriate point-wise CIs were computed. The optimal number of segments of BMI or WHR was selected in order to minimise the Akaike information criterion (Akaike, 1973).

\section{RESULTS}

Table 1 shows the distribution of 454 endometrial cancer cases and 908 controls according to matching variables (age and study centre) and potential confounders. By design, cases and controls had equal distribution of age and study centre. No association was found with education or smoking status. Endometrial cancer risk was inversely associated with age at menarche, parity, and oral contraceptive use, whereas directly associated with age at menopause (Zucchetto et al 2009).

The distribution of endometrial cancer cases and controls, and the corresponding ORs, according to height, weight, BMI at diagnosis and at different ages are shown in Table 2. An inverse association with height was observed $(\mathrm{OR}=0.71 ; 95 \% \mathrm{CI}$ : $0.53-0.95$; for women $\geqslant 165 \mathrm{~cm}$ tall compared with $<160 \mathrm{~cm}$ ). Weight and BMI were directly related to endometrial cancer risk; compared with normal weight women (BMI 20 to $<25 \mathrm{~kg} \mathrm{~m}^{-2}$ ), the ORs were 0.56 (95\% CI: $0.27-1.15)$ in women with BMI $<20,1.41$ (95\% CI: $1.05-1.90)$ and 4.08 (95\% CI: 2.90-5.74) in women with BMI 25 to $<30$ and $\mathrm{BMI} \geqslant 30$, respectively. OR was 1.45 (95\% CI: $1.06-1.98)$ among women who reported to have been heavier than their peer group at age 12 years. Compared with BMI 20 to <25, the OR for BMI $\geqslant 30$ at age 30 was 1.78 (95\% CI: $1.01-3.14$ ), and 3.37 (95\% CI: $2.26-5.04)$ for $\mathrm{BMI} \geqslant 30$ at age 50 (Table 2). Decreases from highest BMI by $\geqslant 2 \mathrm{~kg} \mathrm{~m}^{-2}$ were weakly associated with reductions in endometrial cancer risk (OR vs no decrease in BMI during lifetime $=0.80 ; 95 \%$ CI: $0.59-1.08$ ), but the association disappeared by adjustment for BMI at diagnosis

Table 3 Distribution of 454 endometrial cancer cases and 908 controls, and corresponding odds ratio (OR) with 95\% confidence intervals (Cls), ${ }^{a}$ according to measures of fat distribution, ', Italy, 1992-2006

\begin{tabular}{|c|c|c|c|c|c|}
\hline & \multicolumn{2}{|c|}{ Cases } & \multicolumn{2}{|c|}{ Controls } & \multirow[b]{2}{*}{ OR $(95 \% \mathrm{CI})$} \\
\hline & No. & (\%) & No. & No. & \\
\hline $\begin{array}{l}\text { Waist circumference (cm } \\
\quad<84 \\
84-95 \\
\geqslant 96 \\
\chi^{2} \text { for trend (P-value) }\end{array}$ & $\begin{array}{r}79 \\
101 \\
127\end{array}$ & $\begin{array}{l}(25.7) \\
(32.9) \\
(41.4)\end{array}$ & $\begin{array}{l}221 \\
226 \\
147\end{array}$ & $\begin{array}{l}(37.2) \\
(38.1) \\
(24.8)\end{array}$ & $\begin{array}{c}I^{c} \\
1.22(0.83-1.79) \\
2.68(1.78-4.03) \\
22.51(P<0.01)\end{array}$ \\
\hline $\begin{array}{l}\text { Hip circumference }(\mathrm{cm}) \\
\quad<100 \\
\quad 100 \text { to } 108 \\
\geqslant 109 \\
\chi^{2} \text { for trend (P-value) }\end{array}$ & $\begin{array}{r}87 \\
96 \\
123\end{array}$ & $\begin{array}{l}(28.4) \\
(31.4) \\
(40.2)\end{array}$ & $\begin{array}{l}218 \\
204 \\
170\end{array}$ & $\begin{array}{l}(36.8) \\
(34.5) \\
(28.7)\end{array}$ & $\begin{array}{c}I^{c} \\
1.35(0.92-1.98) \\
2.49(1.66-3.72) \\
18.99(P<0.01)\end{array}$ \\
\hline $\begin{array}{l}\text { Waist-to-hip ratio } \\
\quad<0.833 \\
0.833 \text { to }<0.890 \\
\geqslant 0.890 \\
\chi^{2} \text { for trend ( } P \text {-value) }\end{array}$ & $\begin{array}{r}71 \\
129 \\
106\end{array}$ & $\begin{array}{l}(23.3) \\
(42.2) \\
(34.6)\end{array}$ & $\begin{array}{l}224 \\
177 \\
191\end{array}$ & $\begin{array}{l}(37.8) \\
(29.9) \\
(32.3)\end{array}$ & $\begin{array}{c}I^{c} \\
2.10(1.43-3.09) \\
1.33(0.89-1.97) \\
1.38(P=0.24)\end{array}$ \\
\hline $\begin{array}{l}\text { Waist-to-height ratio } \\
\quad<0.52 \\
0.52 \text { to }<0.59 \\
\geqslant 0.59 \\
\chi^{2} \text { for trend ( } P \text {-value) }\end{array}$ & $\begin{array}{r}77 \\
101 \\
129\end{array}$ & $\begin{array}{l}(25.1) \\
(32.9) \\
(42.0)\end{array}$ & $\begin{array}{l}237 \\
200 \\
155\end{array}$ & $\begin{array}{l}(40.0) \\
(33.8) \\
(26.1)\end{array}$ & $\begin{array}{c}I^{c} \\
1.66(1.12-2.46) \\
3.10(2.03-4.73) \\
27.53(P<0.01)\end{array}$ \\
\hline
\end{tabular}

a ORs from conditional logistic regression models, conditioned on age and study centre, adjusted for year of interview, education, smoking status, age at menarche, age at menopause, oral contraceptives use, parity, and hormone replacement therapy

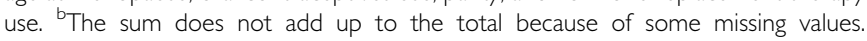
'Reference category.

Table 4 Odds ratio (OR) with 95\% confidence intervals (Cls) af 454 endometrial cancer cases (CA) and 908 controls (CO), according to height, waistto-hip ratio, and waist-to-height ratio in strata of recent body mass index at diagnosis, Italy, 1992-2006

\begin{tabular}{|c|c|c|c|c|c|c|}
\hline & \multicolumn{6}{|c|}{ Body mass index $\left(\mathrm{kg} \mathrm{m}^{-2}\right)$ at diagnosis } \\
\hline & \multicolumn{2}{|c|}{$<\mathbf{2 5}$} & \multicolumn{2}{|c|}{25 to $<30$} & \multicolumn{2}{|c|}{$\geqslant 30$} \\
\hline \multicolumn{7}{|l|}{ Height $(\mathrm{cm})$} \\
\hline$<160$ & $29: 103$ & $1^{\mathrm{b}}$ & $52: 102$ & $1^{\mathrm{b}}$ & $71: 53$ & $1^{b}$ \\
\hline $160-164$ & $42: 126$ & $1.25(0.69-2.25)$ & $53: 110$ & $0.93(0.56-1.54)$ & $53: 44$ & $0.97(0.53-1.79)$ \\
\hline \multicolumn{7}{|l|}{ Waist-to-hip ratio } \\
\hline$<0.833$ & $33: 135$ & $1^{\mathrm{b}}$ & $22: 70$ & $1^{b}$ & $16: 19$ & $1^{\mathrm{b}}$ \\
\hline 0.833 to $<0.890$ & $29: 71$ & $1.70(0.87-3.34)$ & $50: 78$ & $1.74(0.88-3.45)$ & $50: 28$ & $2.95(1.04-8.39)$ \\
\hline$\geqslant 0.890$ & $17: 60$ & $1.01(0.49-2.09)$ & $38: 88$ & $1.11(0.55-2.25)$ & $51: 43$ & $1.17(0.43-3.15)$ \\
\hline \multicolumn{7}{|l|}{ Waist-to-height ratio } \\
\hline$<0.52$ & $55: 195$ & $1^{\mathrm{b}}$ & $22: 41$ & $1^{b}$ & $0: 1$ & $0(-)$ \\
\hline
\end{tabular}

${ }^{a}$ ORs from conditional logistic regression models, conditioned on age and study centre, adjusted for year of interview, education, smoking status, age at menarche, age at

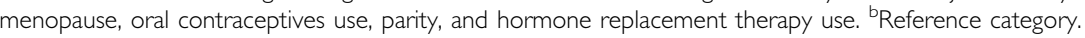


(OR vs no decrease in BMI during lifetime $=0.96 ; 95 \% \mathrm{CI}$ $0.70-1.32$; data not shown).

Table 3 shows the relationship between waist and hip circumferences, WHR, and WHtR and endometrial cancer risk. Significant trends of risk emerged, with the increase of waist circumference (OR for $\geqslant 96$ vs $<84 \mathrm{~cm}$ : 2.68 ; 95\% CI: $1.78-4.03$ ), hip circumference (OR for $\geqslant 109$ vs $<100 \mathrm{~cm}=2.49$; $95 \%$ CI: $1.66-3.72$ ), and WHtR (OR for $\geqslant 0.59 v s<0.52=3.10$; $95 \%$ CI: $2.03-4.73)$. No linear trend in risk, however, was observed for WHR. Compared with the lowest WHR tertile $(<0.833)$, the OR was 2.10 (95\% CI: $1.43-3.09)$ in the intermediate tertile but 1.33 (95\% CI: $0.89-1.97)$ in the highest tertile $(\geqslant 0.890)$.

Table 4 shows the relationship between height, WHR and WHtR, and endometrial cancer risk in strata of BMI at diagnosis. The tendency of height to be inversely associated with risk was restricted to overweight and obese women. An increased risk only in intermediate tertile of WHR was confirmed within all three BMI strata. Conversely, a nonsignificant direct association with WHtR was exclusively observed among normal weight women.

The shapes of the best-fitting regression splines for BMI and WHR are shown in Figure 1. Reference level was set to the median values of BMI (23) and WHR (0.79) of the reference categories in the Tables 2 and 3. The association of endometrial cancer risk with BMI did not show a lower threshold, was monotonic, and risk increase was steeper after a BMI of $\sim 28$ (Figure 1A). Conversely, the relationship between risk and WHR was bell shaped and the corresponding OR was greatest for WHR between 0.86 and 0.87 (Figure 1B). When the associations of endometrial cancer risk with BMI and WHR were examined within strata of women with different characteristics, no statistically significant heterogeneity was observed by education, smoking habit, and occupational or recreational physical activity. However, the association with BMI was somewhat stronger among post-menopausal women (OR for $\mathrm{BMI} \geqslant 30$ vs 20 to $<25=4.94 ; 95 \% \mathrm{CI}: 3.38-7.23)$ than among pre- and peri-menopausal women $(\mathrm{OR}=2.12$; $95 \% \mathrm{CI}$ : $0.92-4.91)$, though this difference was not statistically significant $\left(\chi^{2}\right.$ for heterogeneity $=2.04 ; P=0.36$ ).

Table 5 shows the association of endometrial cancer risk with BMI at ages 30 and 50 years within strata of women who had similar BMI at diagnosis. Some categories of BMI at age 30 and 50 years had to be combined on account of the small numbers reporting large BMI variations. Among women with BMI $<25$ at diagnosis, the OR for BMI $\geqslant 25$ vs $<25$ was 1.24 (95\% CI: $0.49-3.13)$ and 1.59 (95\% CI: $0.71-3.52)$ at ages 30 and 50 years, respectively. Among women with $\mathrm{BMI} \geqslant 30$ at diagnosis, the ORs were 1.23 (95\% CI: $0.54-2.82)$ and 1.60 (95\% CI: 0.52-4.96) for a BMI $\geqslant 30$ vs $<25$ at ages 30 and 50 years, respectively. No association of perceived body size during adolescence and endometrial cancer emerged after stratification for BMI at diagnosis (data not shown).

\section{DISCUSSION}

Our case-control study confirms the strong relationship between weight and BMI at diagnosis and endometrial cancer risk, especially among post-menopausal women. The effect of BMI did not show a lower threshold: but the risk curve became steeper among severely overweight women (BMI >28). After adjustment or stratification by BMI at diagnosis, history of weight loss and BMI in young adulthood did not influence endometrial cancer risk. History of obesity in middle age had, however, a weak nonsignificant adverse effect among obese women aged 50 years or older. These findings provide indirect support to the possibility of weight excess acting as late-stage carcinogens (Parazzini et al 1991; La Vecchia et al 1997). Our BMI results are in broad agreement with previous work and with a meta-analysis that showed summary risk estimates of 1.52 (95\% CI: $1.35-1.72)$ in
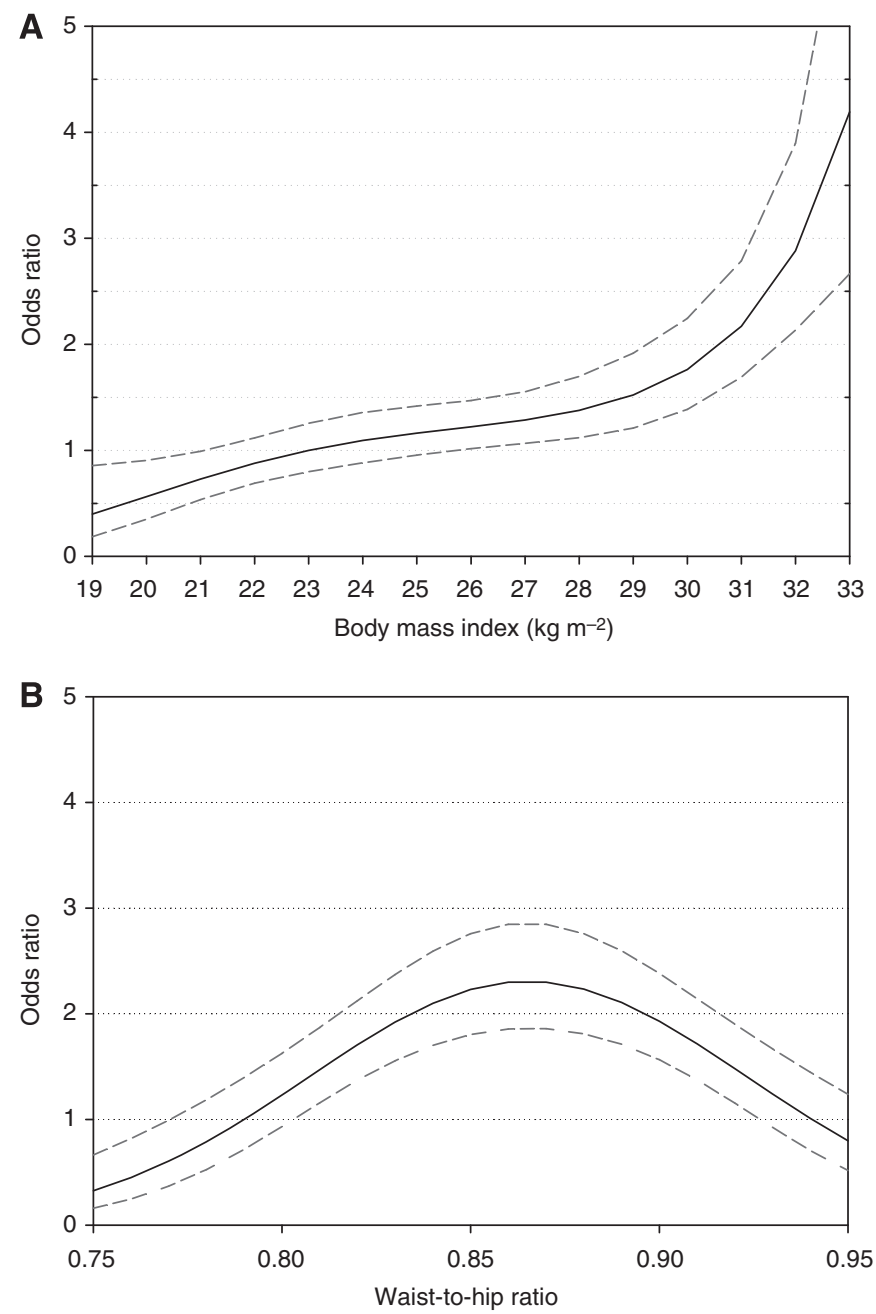

Figure I Estimates of odds ratios and 95\% confidence intervals of endometrial cancer by body mass index at diagnosis $(\mathbf{A})$ and waist-to-hip ratio (B), using cubic regression splines. Italy, 1992-2006 (Odds ratios from regression equations include terms for age, study centre, year of interview, education, smoking status, age at menarche, age at menopause, oral contraceptives use, parity, and hormone replacement therapy use. Curves are shown for best-fitting cubic spline regression models according to Akaike Information Criterion. Dashed lines represent 95\% confidence intervals. Ranges represent the distribution of variables among controls from I0th to 90th percentile). Reference categories were body mass index $=23$ and waist-to-hip ratio $=0.79$

15 cohort studies and 1.56 (95\% CI: $1.45-1.66)$ in 28 case - control studies for an increase of 5 BMI units (WCRF/AICR - World Cancer Research Fund/American Institute for Cancer Research, 2007). The association of BMI with endometrial cancer risk in our study showed no lower threshold and was nonlinear, in agreement with the findings of two meta-analyses (Crosbie et al, 2010; Renehan et al, 2010) that found a highly marked increase in risk for a BMI above 27 .

The relationship between endometrial cancer risk and WHR is less clear. A meta-analysis of one cohort study and four casecontrol studies provided a summary risk estimate of 1.45 (95\% CI: $1.00-2.09$ ) for an increase of 0.1 WHR units (WCRF/AICR - World Cancer Research Fund/American Institute for Cancer Research, 2007). In the Iowa Women's Health cohort study (Folsom et al, 2000) and in a case - control study (Goodman et al, 1997), included in the meta-analysis (WCRF/AICR - World Cancer Research Fund/ American Institute for Cancer Research, 2007), the association 
Table 5 Distribution of 454 endometrial cancer cases and 908 controls, and corresponding odds ratio (OR) with 95\% confidence intervals (Cls) ${ }^{\mathrm{a}}$, by body mass index (BMI) at ages 30 and 50 years in strata of BMI at diagnosis, ${ }^{b}$ Italy, 1992-2006

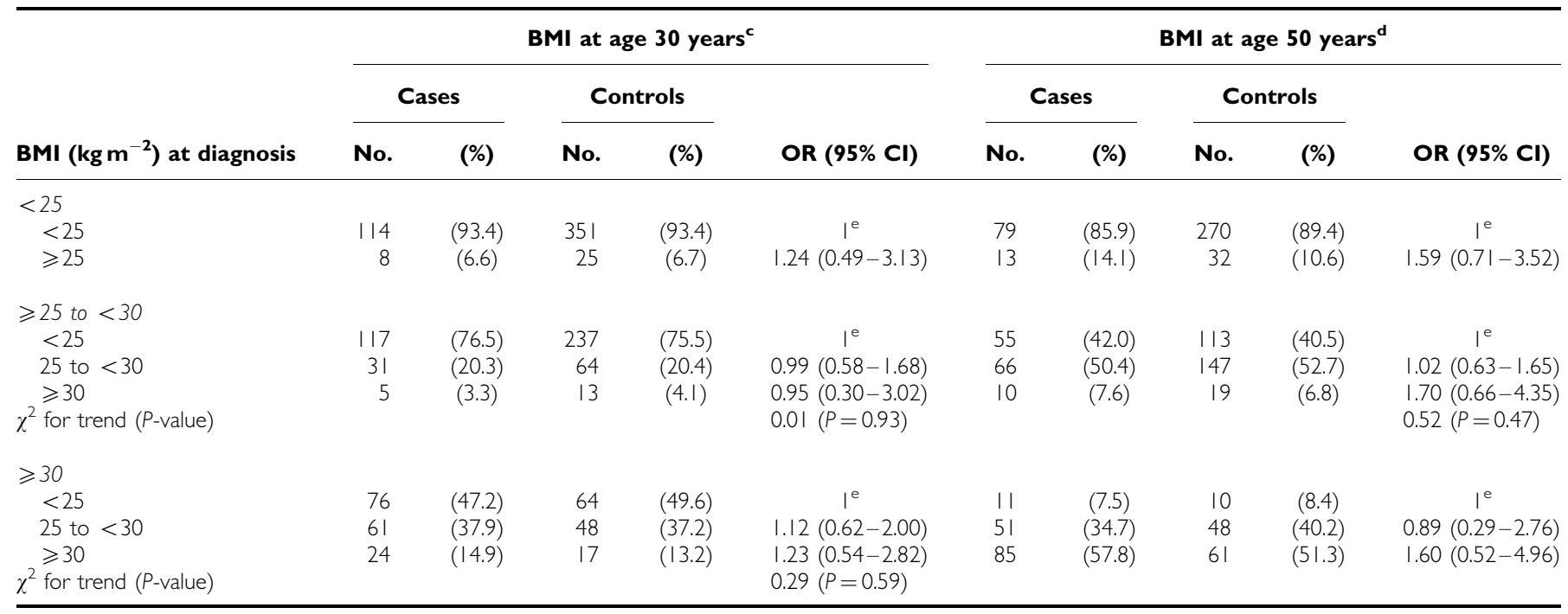

${ }^{\mathrm{a} O R s}$ from conditional logistic regression models, conditioned on age and study centre, adjusted for year of interview, education, smoking status, age at menarche, age at

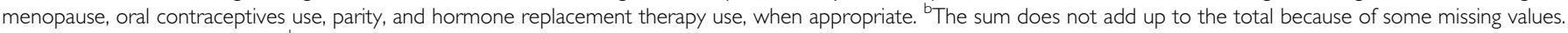

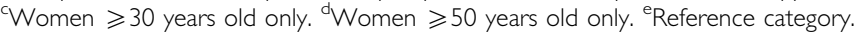

with WHR disappeared after allowance for BMI. Out of three subsequent cohort studies, the European Prospective Investigation into Cancer and nutrition (EPIC; Friedenreich et al, 2007), the Women's Health Study (Conroy et al, 2009), and the California Teachers Study (Canchola et al, 2010), two showed a direct association with WHR (Friedenreich et al, 2007; Canchola et al, $2010)$, but in both studies the upper quantiles of WHR $(>0.83$ and $\geqslant 0.80$, respectively) were lower than in this study. The reasons for a bell-shaped relationship between endometrial cancer risk and WHR are not clear, but may be related to the hormonal correlates of different types of fat distribution. The effect of body fat distribution seemed to be weaker and more complex than the effect of weight excess; risk was clearly associated with both waist and hip circumference, but the relationship with WHR had a bell shape, at least among postmenopausal women ( $80 \%$ of study women).

WHtR is another measure of abdominal adiposity that has been only rarely used in endometrial cancer studies (Canchola et al, 2010). WHtR is considered a measure of visceral fat independent of height. The overall direct association with WHtR in this study was stronger than the association with WHR but seemed to be restricted to normal weight women.

The key interpretation of the relationship between overweight, obesity, and endometrial cancer is in terms of the 'unopposed oestrogen' hypothesis (Key and Pike, 1988, Parazzini et al, 1991), that is, of relative excess of oestrogens, following anovulation in pre-menopause, and androgen conversion to oestrogens in the adipose tissue in post menopause. In the EPIC study, endometrial cancer risk in post-menopausal women was directly associated with the levels of oestrogens and with testosterone, but not with the levels of androstenedione and dehydroepiandrosterone (Allen et al, 2008). These findings may explain the weaker association with WHR than for BMI, in our and other studies (Austin et al, 1991; Shu et al, 1992; Goodman et al, 1997; Folsom et al, 2000; Friedenreich et al, 2007; Conroy et al, 2009). WHR is chiefly a marker of androgenic obesity and hence not strongly related to oestrogen excess (Seidell et al, 1990, 1989). In one study, WHR was associated to breast cancer risk in oestrogen receptor negative, but not in oestrogen receptor positive tumours (Harris et al, 2011).
In agreement with previous work (WCRF/AICR - World Cancer Research Fund/American Institute for Cancer Research, 2007; Crosbie et al, 2010), the association of endometrial cancer risk with BMI was stronger in post-menopausal women than in pre- and peri-menopausal women on account of the stronger importance of oestrogens deriving from androgen conversion after ovarian activity had ceased. No risk correlates other than menopausal status modified the association with BMI in our study.

Only a few studies have considered the relationship with lifetime history of body weight and endometrial cancer risk. A meta-analysis of BMI in young adulthood showed summary estimates of $1.31(95 \%$ CI: $1.12-1.54)$ per 5 BMI unit increase, based on three cohort studies. The corresponding value, based on six case - control studies, was 1.10 (95\% CI: 0.95-1.27; WCRF/AICR - World Cancer Research Fund/American Institute for Cancer Research, 2007). Four prospective studies showed a significant direct association between weight gain during life (measured as weight or BMI variation; Schouten et al, 2004; Chang et al, 2007; Friedenreich et al, 2007; Park et al, 2010), whereas another showed no association (Terry et al, 1999). Five case-control studies also reported a direct association of weight gain with endometrial cancer risk (Levi et al, 1992; Swanson et al, 1993; Olson et al, 1995; Xu et al, 2005; Trentham-Dietz et al, 2006), whereas another study found no relationship (Weiderpass et al, 2000). A case-control study from China showed a direct relation with weight at $\geqslant 50$ years, but not at younger age (Shu et al, 1992). In our study, we made a special effort to separate the effects of BMI in young adulthood and middle age and of lifetime weight changes from the effect of BMI at cancer diagnosis or interview (controls). We found no evidence of an influence of history of overweight and obesity after stratification by BMI at diagnosis. Our findings are, therefore, consistent with excess weight affecting only late carcinogenesis stages. Only obesity at age 50 years showed an association of borderline statistical significance among women older with $\mathrm{BMI} \geqslant 30$ at diagnosis. This finding is compatible with an effect of duration of exposure to high levels of circulating oestrogen levels after menopause.

No association or a weak direct association has been reported between height and endometrial cancer risk (WCRF/AICR - World Cancer Research Fund/American Institute for Cancer Research, 
2007; Friedenreich et al, 2007; Park et al, 2010). Conversely, we found a weak inverse association, in agreement with some previous Italian (La Vecchia et al, 1997) and Swiss studies (Levi et al, 1992). However, in our study the association with height was restricted to overweight and obese women and was accompanied by a tendency of control women having $\mathrm{BMI} \geqslant 25$ to be shorter than leaner women (data not shown).

Case-control studies may be subject to selection and information bias (Breslow and Day, 1980). However, possible sources of selection bias are limited in our study, as cases and controls were drawn from the same catchment areas, participation was almost complete, and women with diseases potentially related to diet and dietary modifications were excluded from the control group. The high proportion of missing values for WHR cannot be a source of bias as it derives from lack of measurement of waist or hip in the vast majority of women from one centre.

In our study, weights during lifetime and height were selfreported. It is known that most individuals, and especially those overweight, tend to underestimate their weight (WCRF/AICR World Cancer Research Fund/American Institute for Cancer Research, 2007). Conversely, height tends to be systematically overestimated (WCRF/AICR - World Cancer Research Fund/ American Institute for Cancer Research, 2007). As for lifetime weight history, past body measures were generally well correlated with corresponding measures (Casey et al 1991), even in older people (Klipstein-Grobusch et al, 1998). A differential recall between cases and control is possible, but we do not think that weight and height were differentially reported by cases and controls. All women in our study were interviewed in similar hospital settings, and the general population was unaware of the possible link between anthropometric measures and endometrial cancer. In addition, opposite to many other cancers, endometrial cancer is not frequently preceded by weight loss (De Vita et al, 2007).

Confounding was dealt with in our study by adjusting for a broad range of risk correlates, including reproductive and hormone-related factors. Less than $6 \%$ of women reported any use of lifetime hormone replacement therapy for 2 or more years
(Zucchetto et al, 2009), thus avoiding the need to exclude users from the assessment of the effects of anthropometric measures.

The implications of this report from a public health viewpoint are clear. The fraction of endometrial cancer cases attributable to overweight and obesity in our study population was of $41 \%$ (95\% CI: 31-51\%; Mezzetti et al, 1996), even higher than the estimated $30 \%$ (95\% CI: $26-34 \%$ ) reported for the combination of 30 European countries (Renehan et al, 2010). The predominant importance of recent weight, compared to lifetime history, justifies encouraging weight reduction in women at any age.

\section{ACKNOWLEDGEMENTS}

We thank Mrs I Garimoldi and L Mei for editorial assistance, Mrs M Volpato for study coordination, and Mrs G Bessega, L Zaina, and Dr M Grimaldi, Dr O Manganelli, and Dr R Cozzi for data collection. We also are grateful to Dr E Campagnutta (Gynecologic Oncology Depatment, IRCCS 'Centro di Riferimento Oncologico', Aviano), Dr G Boz (Radiotherapy Department, IRCCS 'Centro di Riferimento Oncologico', Aviano), Dr S Tumolo (Unit of Oncology, General Hospital, Pordenone), Dr S Greggi (Gynecology Department, IRCCS 'G Pascale', Napoli), Dr G Chiara (I General Surgery Department, General Hospital, Pordenone), Dr G Tosolini (II General Surgery Department, General Hospital, Pordenone), Dr E Trevisanutto (Dermatology Department, General Hospital, Pordenone), Dr A Mele (Hand Surgery and Microsurgery Department, General Hospital, Pordenone), Dr L Forner (Eye Diseases Department, General Hospital, Pordenone) and Dr P Aseni (Transplant Department Niguarda Cà Granda Hospital, Milan) for providing cancer cases and control patients. This work was supported by the Italian Association for Cancer Research.

\section{Conflict of interest}

The authors declare no conflict of interest.

\section{REFERENCES}

Akaike H (1973) Information theory and an extension of the maximum likelihood principle. In Second International Symposium on Information Theory, BN Petrov and F Csaki (eds), pp 267-281. Akademiai Kiado: Budapest. (reproduced (1992) in Breakthroughs in Statistics 1, S Kotz and N L Johnson (eds), Springer-Verlag: New York, pp 610-624)

Allen NE, Key TJ, Dossus L, Rinaldi S, Cust A, Lukanova A, Peeters PH, Onland-Moret NC, Lahmann PH, Berrino F, Panico S, Larrañaga N, Pera G, Tormo MJ, Sánchez MJ, Ramón Quirós J, Ardanaz E, Tjønneland A, Olsen A, Chang-Claude J, Linseisen J, Schulz M, Boeing H, Lundin E, Palli D, Overvad K, Clavel-Chapelon F, Boutron-Ruault MC, Bingham S, Khaw KT, Bueno-de-Mesquita HB, Trichopoulou A, Trichopoulos D, Naska A, Tumino R, Riboli E, Kaaks R (2008) Endogenous sex hormones and endometrial cancer risk in women in the European Prospective Investigation into Cancer and Nutrition (EPIC). Endocr Relat Cancer 15: $485-497$

Austin H, Austin Jr JM, Partridge EE, Hatch KD, Shingleton HM (1991) Endometrial cancer, obesity, and body fat distribution. Cancer Res 51: $568-572$

Breslow N, Day N (1980) The Analysis of Case-Control Studies. no. 32, Vol I. IARC Scientific Publication: Lyon, France

Calle EE, Rodriguez C, Walker-Thurmond K, Thun MJ (2003) Overweight, obesity, and mortality from cancer in a prospectively studied cohort of U. S Adults N Engl J Med 348: $1625-1638$

Canchola AJ, Chang ET, Bernstein L, Largent JA, Reynolds P, Deapen D, Ursin G, Horn-Ross PL (2010) Body size and the risk of endometrial cancer by hormone therapy use in postmenopausal women in the California Teachers Study Cohort. Cancer Causes Control 21: $1407-1416$
Casey VA, Dwyer JT, Berkey CS, Coleman KA, Gardner J, Valadian I (1991) Long-term memory of body weight and past weight satisfaction: a longitudinal follow-up study. Am J Clin Nutr 53: $1493-1498$

Chang SC, Lacey Jr JV, Brinton LA, Hartge P, Adams K, Mouw T, Carroll L, Hollenbeck A, Schatzkin A, Leitzmann MF (2007) Lifetime weight history and endometrial cancer risk by type of menopausal hormone use in the NIH-AARP diet and health study. Cancer Epidemiol Biomarkers Prev 16: $723-730$

Conroy MB, Sattelmair JR, Cook NR, Manson JE, Buring JE, Lee IM (2009) Physical activity, adiposity, and risk of endometrial cancer. Cancer Causes Control 20: 1107-1115

Crosbie EJ, Zwahlen M, Kitchener HC, Egger M, Renehan AG (2010) Body mass index, hormone replacement therapy, and endometrial cancer risk: a meta-analysis. Cancer Epidemiol Biomarkers Prev 19: 3119-3130

Dal Maso L, Zucchetto A, Tavani A, Montella M, Ramazzotti V, Talamini R, Canzonieri V, Garbeglio A, Negri E, Tonini A, La Vecchia C, Franceschi S (2007) Renal cell cancer and body size at diferent ages: an Italian case-control study. Am J Epidemiol 166: 582-591

De Vita, VT Jr, Hellman TS, Rosenberg SA (2007) De Vita, Hellman, and Rosenberg's Cancer: Principles \& Practice of Oncology, 8th edn. Wolters Kluwer: London

Folsom AR, Kushi LH, Anderson KE, Mink PJ, Olson JE, Hong CP, Sellers TA, Lazovich D, Prineas RJ (2000) Associations of general and abdominal obesity with multiple health outcomes in older women: the Iowa Women's Health Study. Arch Intern Med 160: 2117-2128

Friedenreich C, Cust A, Lahmann PH, Steindorf K, Boutron-Ruault MC, Clavel-Chapelon F, Mesrine S, Linseisen J, Rohrmann S, Boeing $H$, Pischon T, Tjønneland A, Halkjaer J, Overvad K, Mendez M, 
Redondo ML, Garcia CM, Larrañaga N, Tormo MJ, Gurrea AB, Bingham S, Khaw KT, Allen N, Key T, Trichopoulou A, Vasilopoulou E, Trichopoulos D, Pala V, Palli D, Tumino R, Mattiello A, Vineis P, Bueno-de-Mesquita HB, Peeters PH, Berglund G, Manjer J, Lundin E, Lukanova A, Slimani N, Jenab M, Kaaks R, Riboli E (2007) Anthropometric factors and risk of endometrial cancer: the European prospective investigation into cancer and nutrition. Cancer Causes Control 18: 399-413

Goodman MT, Hankin JH, Wilkens LR, Lyu LC, McDuffie K, Liu LQ, Kolonel LN (1997) Diet, body size, physical activity, and the risk of endometrial cancer. Cancer Res 57: 5077-5085

Greenland S (1995) Dose-response and trend analysis in epidemiology: alternatives to categorical analysis. Epidemiology 6: 356-365

Harris HR, Willett WC, Terry KL, Michels KB (2011) Body Fat Distribution and Risk of Premenopausal Breast Cancer in the Nurses' Health Study II. J Natl Cancer Inst 103(3): 273-278

Key TJ, Pike MC (1988) The dose-effect relationship between 'unopposed' oestrogens and endometrial mitotic rate: its central role in explaining and predicting endometrial cancer risk. Br J Cancer 57: 205-212

Klipstein-Grobusch K, Kroke A, Boeing H (1998) Reproducibility of selfreported past body weight. Eur J Clin Nutr 52: 525-528

La Vecchia C, Negri E, Franceschi S, Levi F (1997) An epidemiological study of endometrial cancer, nutrition and health. Eur J Cancer Prev 6: $171-174$

Le Marchand L, Wilkens LR, Mi MP (1991) Early-age body size, adult weight gain and endometrial cancer risk. Int J Cancer 48: 807-811

Levi F, La Vecchia C, Negri E, Parazzini F, Franceschi S (1992) Body mass at different ages and subsequent endometrial cancer risk. Int J Cancer 50: $567-571$

Lucenteforte E, Talamini R, Montella M, Dal Maso L, Tavani A, Deandrea S, Pelucchi C, Greggi S, Zucchetto A, Barbone F, Parpinel M, Franceschi S, La Vecchia C, Negri E (2008) Macronutrients, fatty acids and cholesterol intake and endometrial cancer. Ann Oncol 19: 168-172

Mezzetti M, Ferraroni M, Decarli A, La Vecchia C, Benichou J (1996) Software for attributable risk and confidence interval estimation in casecontrol studies. Comput Biomed Res 29: 63-75

Olson SH, Trevisan M, Marshall JR, Graham S, Zielezny M, Vena JE, Hellmann R, Freudenheim JL (1995) Body mass index, weight gain, and risk of endometrial cancer. Nutr Cancer 23: 141 - 149

Parazzini F, La Vecchia C, Bocciolone L, Franceschi S (1991) The epidemiology of endometrial cancer. Gynecol Oncol 41: 1-16

Park SL, Goodman MT, Zhang ZF, Kolonel LN, Henderson BE, Setiawan VW (2010) Body size, adult BMI gain and endometrial cancer risk: the multiethnic cohort. Int J Cancer 126: 490 - 499

Renehan AG, Soerjomataram I, Tyson M, Egger M, Zwahlen M, Coebergh JW, Buchan I (2010) Incident cancer burden attributable to excess body mass index in 30 European countries. Int J Cancer 126: 692-702
Rosenberg PS, Katki H, Swanson CA, Brown LM, Wacholder S, Hoover RN (2003) Quantifying epidemiologic risk factors using non-parametric regression: model selection remains the greatest challenge. Stat Med 22: $3369-3381$

Schapira DV, Kumar NB, Lyman GH, Cavanagh D, Roberts WS, LaPolla J (1991) Upper-body fat distribution and endometrial cancer risk. JAMA 266: 1808 -1811

Schouten LJ, Goldbohm RA, van den Brandt PA (2004) Anthropometry, physical activity, and endometrial cancer risk: results from the Netherlands Cohort Study. J Natl Cancer Inst 96: 1635-1638

Seidell JC, Cigolini M, Charzewska J, Ellsinger BM, Di Biase G, Björntorp P, Hautvast JG, Contaldo F, Szostak V, Scuro LA (1990) Androgenicity in relation to body fat distribution and metabolism in 38-year-old women-the European Fat Distribution Study. J Clin Epidemiol 43: $21-34$

Seidell JC, Cigolini M, Deurenberg P, Oosterlee A, Doornbos G (1989) Fat distribution, androgens, and metabolism in nonobese women. Am J Clin Nutr 50: 269-273

Shu XO, Brinton LA, Zheng W, Swanson CA, Hatch MC, Gao YT, Fraumeni Jr JF (1992) Relation of obesity and body fat distribution to endometrial cancer in Shanghai, China. Cancer Res 52: 3865-3870

Swanson CA, Potischman N, Wilbanks GD, Twiggs LB, Mortel R, Berman ML, Barrett RJ, Baumgartner RN, Brinton LA (1993) Relation of endometrial cancer risk to past and contemporary body size and body fat distribution. Cancer Epidemiol Biomarkers Prev 2: 321-327

Terry P, Baron JA, Weiderpass E, Yuen J, Lichtenstein P, Nyren O (1999) Lifestyle and endometrial cancer risk: a cohort study from the Swedish Twin Registry. Int J Cancer 82: 38-42

Trentham-Dietz A, Nichols HB, Hampton JM, Newcomb PA (2006) Weight change and risk of endometrial cancer. Int J Epidemiol 35: 151-158

Weiderpass E, Persson I, Adami HO, Magnusson C, Lindgren A, Baron JA (2000) Body size in different periods of life, diabetes mellitus, hypertension, and risk of postmenopausal endometrial cancer (Sweden). Cancer Causes Control 11: 185-192

WCRF/AICR - World Cancer Research Fund/American Institute for Cancer Research (2007) Food, nutrition, physical activity, and the prevention of cancer: a Global Perspective. AICR: Washington DC

Xu WH, Xiang YB, Zheng W, Zhang X, Ruan ZX, Cheng JR, Gao YT, Shu XO (2006) Weight history and risk of endometrial cancer among Chinese women. Int J Epidemiol 35: 159-166

Xu WH, Matthews CE, Xiang YB, Zheng W, Ruan ZX, Cheng JR, Gao YT, Shu XO (2005) Effect of adiposity and fat distribution on endometrial cancer risk in Shanghai women. Am J Epidemiol 161: 939-947

Zucchetto A, Serraino D, Polesel J, Negri E, De Paoli A, Dal Maso L, Montella M, La Vecchia C, Franceschi S, Talamini R (2009) Hormonerelated factors and gynecological conditions in relation to endometrial cancer risk. Eur J Cancer Prev 18: 316-321 